\title{
Transparent Ceramics
}

Reliable joining of new materials often requires the use of adhesive bonding technology. Against this background, adhesive engineers may be interested to know that the ceramic manufacturer CeramTec has now succeeded in producing transparent ceramics on a series-production scale. The new material is called Perlucor and was presented for the first time at the Hannover Fair.

Derlucor is a highly pure material with a number of extraordinary mechanical, chemical, thermal and optical properties. With a high transparency of more than $80 \%$ - which is equivalent to a relative transparency of over $90 \%$ the material opens up new fields of application wherever glass reaches its limits. In addition to its high transparency, Perlucor also has three to four times the hardness and strength of conventional glass. This makes it well suited for use in extreme wear conditions, for example in mechanical, plant or equipment engineering. The developers also see application possibilities in the field of medical engineering and in the areas of optical applications, architecture, jewellery and design.

\section{Thermal and chemical stability}

The new material has higher thermal stability than glass (by a factor of three). This makes it suitable for use at temperatures of up to 1,600 degrees Celsius. For example, the transparent ceramic can be used as an inspection window in high-temperature furnaces. Due to its purity, Perlucor also features extraordinarily high chemical stability, which means that it can also be used with highly concentrated acids and lyes.

The standard Perlucor tile size is $90 \times 90 \mathrm{~mm}$. Individual contours based on customer specifications can also be manufactured from this format. Perlucor panel thickness can be individually tailored to a tenth of a millimetre. Standard tiles can be combined into multi-tile composites to create large

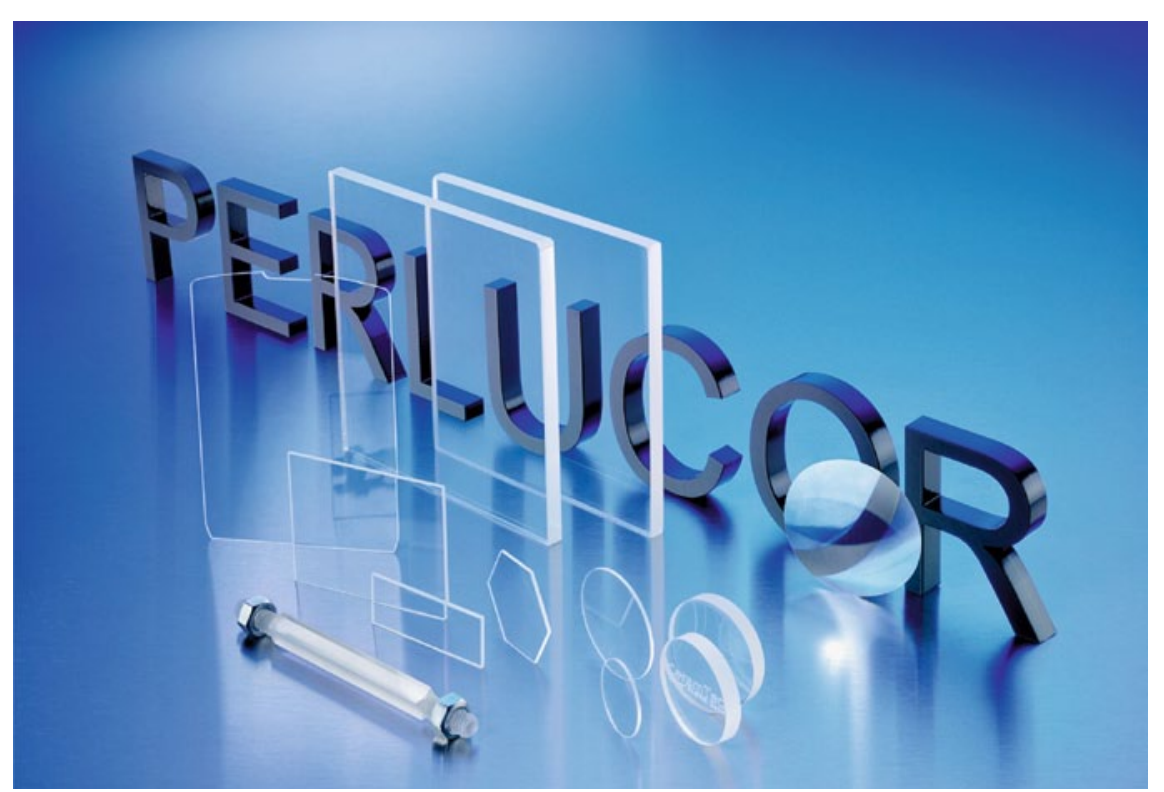

Ceramtec $\mathrm{GmbH}$ is the first European company to succeed in producing the transparent

ceramic Perlucor on a series-production scale.

surfaces. The edges are joined using a method specially developed by CeramTec in such a way that the joints become "invisible" due to the different refractive index of the ceramic and the adhesive, thus creating a continuously transparent surface.

For further information, please visit: www.ceramtec.de

\section{Vermittelt überzeugend neben Fachtermini auch sprachliche Strukturen}

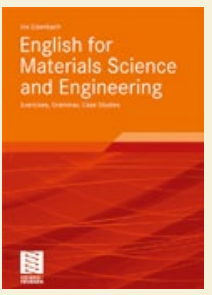

Iris Eisenbach

English for Materials Science and Engineering

Exercises, Grammar, Case Studies

2011. VIII, $109 \mathrm{~S}$. Br. EUR 24,95

ISBN 978-3-8348-0957-5

Einfach bestellen: fachmedien-service@springer.com Telefax $+49(0) 6221 / 345-4229$ 